\title{
The USC-OSA Student Chapter: goals and benefits for the optics community
}

\section{A. Gómez-Varela, Ana Gargallo, Héctor González Núñez, Tamara Delgado-García, Citlalli Almaguer-Gómez, et al.}

A. I. Gómez-Varela, Ana Gargallo, Héctor González Núñez, Tamara DelgadoGarcía, Citlalli Almaguer-Gómez, F. Cambronero-López, M. T. Flores-Arias, "The USC-OSA Student Chapter: goals and benefits for the optics community," Proc. SPIE 9289, 12th Education and Training in Optics and Photonics Conference, 92892T (17 July 2014); doi: 10.1117/12.2070767

Event: 12th Education and Training in Optics and Photonics Conference, 2013, Porto, Portugal 


\title{
The USC-OSA Student Chapter: goals and benefits for the optics community
}

\author{
A.I. Gómez-Varela ${ }^{\mathrm{a}}$, Ana Gargalloa ${ }^{\mathrm{a}}$, Héctor González-Núñez ${ }^{\mathrm{a}}$, Tamara Delgado-García ${ }^{\mathrm{a}}$, Citlalli \\ Almaguer-Gómez ${ }^{\mathrm{a}}$, F. Cambronero-López and M.T. Flores-Arias ${ }^{\mathrm{a} 2}$ \\ ${ }^{a}$ Departamento de Física Aplicada (Área de Óptica), Facultade de Física, Campus Vida s/n, \\ Universidade de Santiago de Compostela, 15782 Santiago de Compostela, Spain
}

\begin{abstract}
The USC-OSA Student Chapter has been constituted in March 2013 by members of the University of Santiago de Compostela (USC) in Spain and sponsored by The Optical Society of America (OSA). It is formed by five graduate and one undergraduate students with the common interest in Optics and Photonics research and a professor of the USC is also involved as a faculty advisor. We decided to start this group with the aim of involving kids, precollege and undergraduate students in the world of Optics and Photonics. The activities that the USC-OSA Student Chapter members intend to realize are mainly educational tasks for the spreading of knowledge in Photonics by means of basic experiments, demonstrations and lectures by leading researchers and teachers. Most of the needed resources to accomplish these activities are provided by the OSA, such as educational posters and a portable kit for demonstrating Optics to students. At this moment the USC-OSA Student Chapter is carrying out several activities, as educational journeys at the Santiago de Compostela University Hospital Complex (CHUS), where hospitalized children can approach to Optics through some simple experiments and games. A teaching program is also being organized in collaboration with Galician secondary schools in order to show students the importance and uses of Optics and Photonics and to arouse their interest in this field, as well as encouraging them to develop their scientific thinking. Another activity will take place in November during the Science Week, which includes a program of lectures targeted to undergraduate students and an exposition of several demonstrations
\end{abstract}

Keywords: youth education, student chapter, divulgation activities, spreading of Optics and Photonics

\section{INTRODUCTION}

With the aim of promoting the Optics knowledge into the community, professional societies have created the figure of student chapters, which are groups of students with studies related to Optics and Photonics. They receive funding and networking from an international organization with the goal of increasing the interest in Optics in precollege students and provide professional development of its members. In our case, we decided to start a chapter with the Optical Society of America (OSA); this is an organization whose mission is to promote the generation, application and archiving of knowledge in Optics and Photonics and to disseminate this knowledge worldwide since 1916.

In 2002 the OSA established a non-profit organization for keeping with its mission, the OSA Foundation ${ }^{1}$, which supports programs that advance youth science education, enriches Optics and Photonics education in developing nations,

\footnotetext{
${ }^{1}$ usc.osa.sc@gmail.com; phone +34881813530;

2 maite.flores@usc.es; phone +34881813502
} 
provides professional development resources to college-level students and recognizes technical and business excellence. The OSA Foundation finances several grant programs, competitions and events that benefit Student Chapters and their members.

It is important the knowledge of fundamental experiments and techniques for the spreading of Optics and Photonics in schools and high schools, but it is also important the people who develop this activities into the community and bring it closer to teachers and students. We think that an organized group works better than an individual person and takes less effort for its members.

\subsection{Student Chapter members benefits}

The societies focused on Optics and Photonics support the activities developed by student chapters and provide them with many benefits that help chapter members building leadership skills and advancing their career as, for instance, grants which support professional development, youth education outreach and travel support for one representative member of the chapter per year to attend a Leadership Conference.

The activities for professional development include events to promote the chapter or recruit new members, events held in cooperation with other chapters or societies, technical sessions, lectures, networking and social events. Chapters receive funding for a guest speaker of their choice on an annual basis. Besides, OSA provides a webhosting to promote chapter activities and the networking includes the creation of a profile in social network as Facebook, Twitter, etc.

Chapters receive support for youth education events, including classroom demonstrations or science fairs. OSA also provides material for carrying out such activities, as the optics suitcase (an educational interactive package, designed to introduce different concepts related to the study of light to middle school students), posters, books, online resources, etc.

\subsection{USC-OSA Student Chapter foundation}

We have founded an OSA Student Chapter at the University of Santiago de Compostela (USC), called USC-OSA Student Chapter $^{2}$, with the aim of involving kids, precollege and undergraduate students in the world of Optics and Photonics by means of educational tasks, divulgation lectures, fundamental experiments and demonstrations. We want to make Optics and Photonics more visible into the society and arouse the interest of precollege students in this science.

Since its inception in March 2013, the USC-OSA members have participated in several activities that will be described in next section of this paper. Moreover, we already have several programmed activities for this year.

USC-OSA is composed of graduate and undergraduate students and a professor of the same university who is involved as faculty advisor. There are four students who have specific tasks in the chapter that are called officers (president, vicepresident, treasurer and secretary). This structure helps us to organize the educational and social activities.

\section{USC-OSA STUDENT CHAPTER PAST ACTIVITIES}

Even though the USC-OSA Student Chapter recent foundation, several activities have already been carried out. The first of these activities was a lecture given by Larry Thibos, professor at Indiana University and an internationally recognized expert in visual and physiological optics. The presentation of professor Thibos, entitled "Ocular Wavefront Tomography (OWT): Describing and correcting the eye's optical system over a wide field of view", was imparted at the Faculty of Optics and Optometry at the USC, in the presence of different members of the university community (undergraduate and graduate students, associate professors, etc.). Besides, some people could attend the conference from their own university or home using an online platform called Adobe $\odot$ Connect ${ }^{\mathrm{TM}}$. We will be using this platform in future lectures to make possible that all that people who want to enjoy the conferences can do it, even thought they can not be at the place where they are imparted.

The second activity of the USC-OSA Chapter was dedicated to astronomy. The activity consisted of two sessions, being one of them an introductory lecture, imparted by Prof. Salvador Bará Viñas of the USC, about what we can observe in the sky without the need of professional optical systems nor deep knowledge in the field. The audience of this lecture was very inhomogeneous, being composed by members of the university community as well as by people unrelated to it. The second part of the activity was an introduction to astronomical observations with telescopies in the Campus Vida at 
the USC, also conducted by Prof. Bará. During this workshop the attendants could observe by themselves different celestial bodies, as shown in Figure 1.

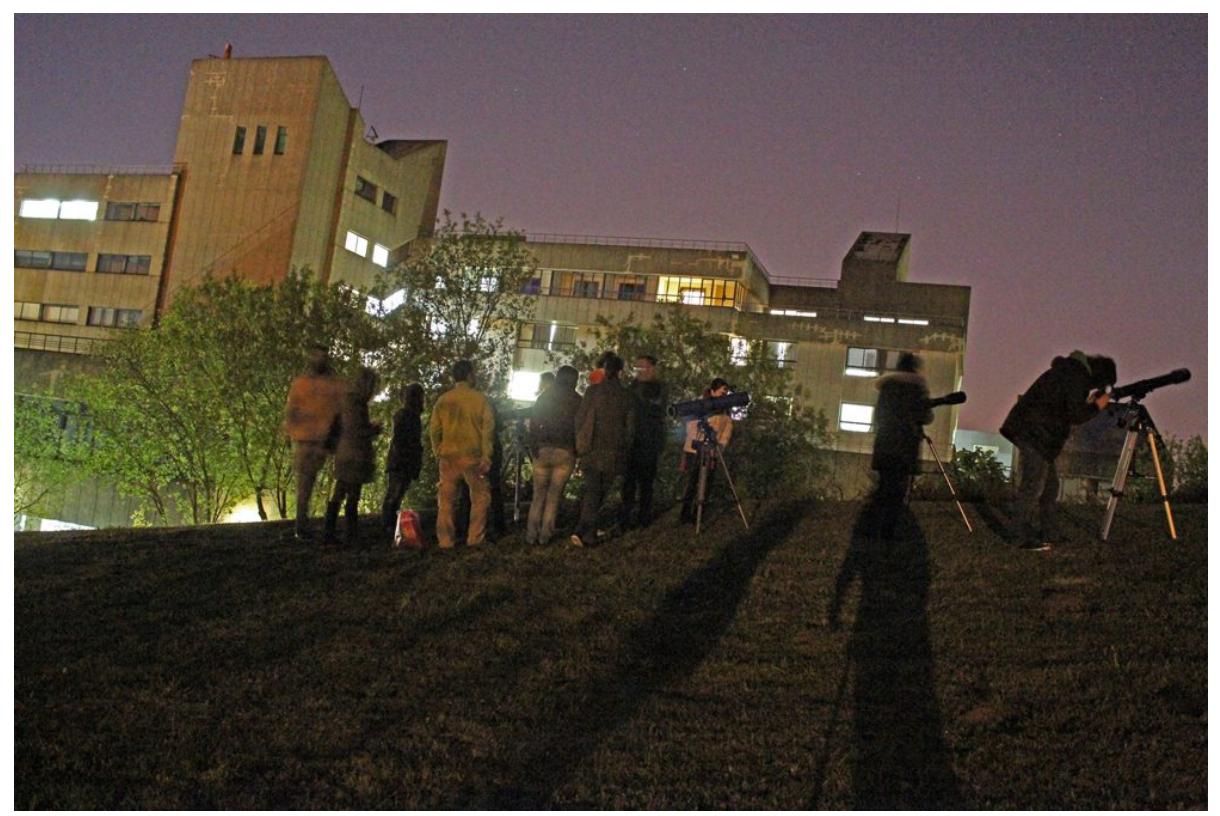

Figure 1. Attendants to the workshop "Introduction to astronomical observations" imparted at the USC.

The last two actions of the USC-OSA Student Chapter were intended for kids. The first one was carried out at the USC University Hospital Complex (CHUS) in Santiago de Compostela. In this occasion the main object of the Chapter was to break the daily routine of about fifteen hospitalized children of different ages by doing some experiments and activities to show them how the light works, at the same time that they had some fun. First we showed children how they could fabricate their own kaleidoscope with ordinary, cheap materials and explain them how this element works. Once they finished building the kaleidoscopes, we proposed them to "make" a rainbow in the room using an overhead projector and a prism. We also showed them how we can obtain different colors by mixing the additive primary light colors, being red, green and blue those normally used in the additive color system. To realize this experience we used the overhead projector and a set of mirrors. The three primary colors (filters) are placed over the projector. Then, with the aid of the mirrors, the colors are projected on a white wall separately and next, by adjusting the position of the mirrors, they are superposed in pairs to see the new colors created. Finally the three primary colors are superimposed in order to show the kids how white light can be obtained. For the last of the experiences we prepared a chromatic disk that children colored and cut by themselves. Then, they pieced the middle of the disc and inserted a pencil through the whole and spin the disc in order to prove, in a simple way, that white color is a mixture of other colors.

Finally, the last activity this academic year was realized at the primary school "Colegio de Educación Infantil y Primaria de Vite I", located in Santiago de Compostela. About forty children of primary school participated in this activity, which main aim was to awake their curiosity about Optics and promote their interest for learning. The session started with a short presentation to explain the children some basic concepts about light and vision, then we repeated the experiences of decomposition of white light with a prism and the obtaining of secondary colors from the primary ones, experiences that we had already done at the hospital. In this activity, we also introduced them to the concept of polarization of light using an overhead projector, different large linear polarizing filters and some device with a LCD monitor, as a mobile phone or a laptop. We showed to the children the effects produced on a white screen with two linear polarizing filters and the difference among them when we rotate one to each other. Next, using ordinary, transparent plastic materials as a ruler, set-square, glasses or plastic wrap, among others, we could explain them the appearance of colorful patterns when locating those objects among two linear polarizing filters and project them on the screen. In addition, we explained the refraction of light and carried out some other fundamental experiments as the Tyndall effect in liquids by using a laser 
pointer to introduce the concept of guided light. In the second part of the session with primary school children we showed them how to build a kaleidoscope and a chromatic disk, as we can see in Figure 2 and Figure 3, respectively.
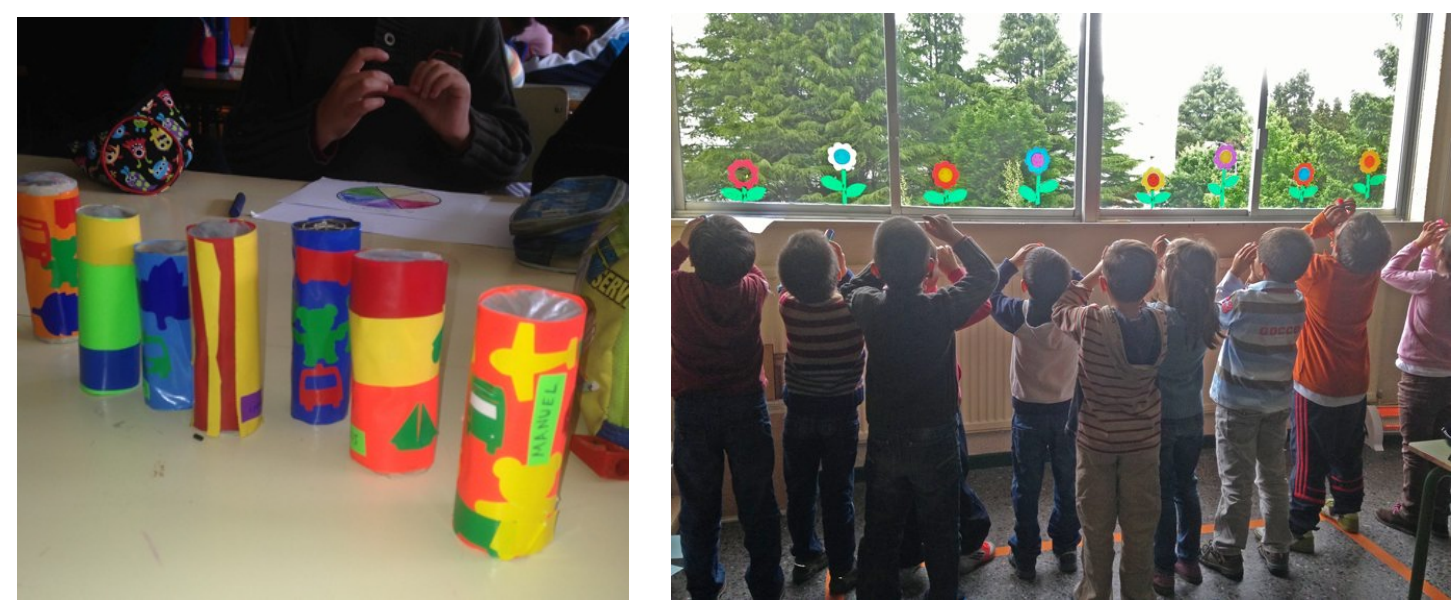

Figure 2. Kaleidoscopes made by the children (left) and the children observing the patterns produced by their kaleidoscopes (right).
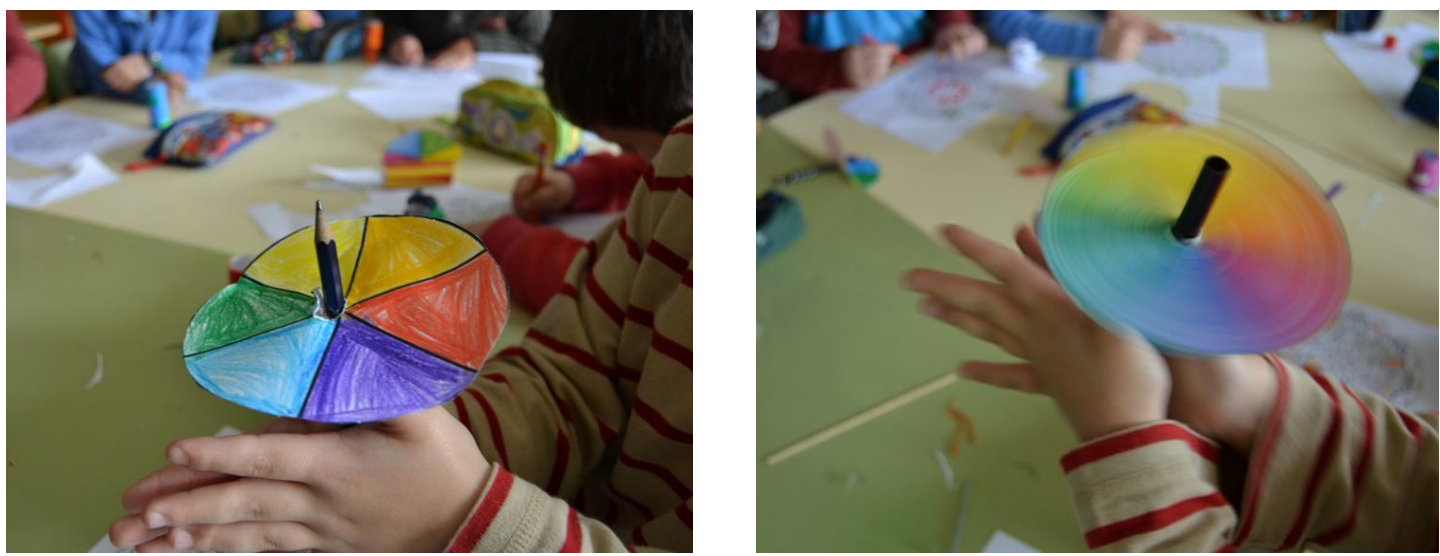

Figure 3. One of the children spinning the chromatic disk that has just colored and cut.

\section{FUTURE EVENTS OF THE USC-OSA STUDENT CHAPTER}

With the aim of approaching optics knowledge to primary and secondary students and getting their interest towards this field, the USC-OSA Student Chapter intends to organize different activities along the 2013-2014 academic year. One of them will be an activity called "Week of Science focused on Optics and Photonics". This activity will consist of some workshops where the students can play with light and discover some optical properties. In the same way, we also want to include in this event several lectures and experiments related to Optics and Photonics orientated to secondary school and undergraduate students.

In order to continue with the actions started this academic year, we are intending to organize more visits to the USC University Hospital Complex and local high schools. In these visits we will explain the influence of Optics and Photonics in our lives to children and realize some basic experiments with them.

Besides these activities the USC-OSA Student Chapter will organize several actions for the professional development of its members, consisting on advanced lectures and workshops imparted by people working in topics related to Optics and Photonics. These actions will help us to improve our technical and researching skills, as well as to identify possible 
partnerships in our area. People studying, working or planning to work in Optics, Photonics, or in a related field will also have the opportunity to attend any of these sessions.

Moreover, the USC-OSA has established collaborations with the Spanish Society of Optics (SEDOPTICA), the EOS Comunidad Valenciana Student Club and with the Galician Society of Clinic Optometry (SGOC). In cooperation with SEDOPTICA and the EOS Comunidad Valenciana Student Club, we are organizing the First Meeting of Young Researchers in Optics that will be held in Valencia in July 2013. On the other hand, along with the SGOC, we are planning several sessions where members of USC-OSA and student members of Galician Clinic Optometry Society (SGOC) will learn about research topics as how to write a scientific paper, patents, spin-offs, technical sessions about Optics and Photonics research in the University of Santiago de Compostela, etc. Besides, the SGOC organizes a national meeting in November 23th where the USC-OSA Student Chapter will collaborate and present the chapter to professionals in Optics and Optometry.

\section{CONCLUSIONS}

The student chapters are a great opportunity to bring science closer to the public of all ages, stimulate the taste for scientific knowledge and encourage the participation of citizens in scientific matters through informative and entertaining initiatives. In particular, the USC-OSA Student Chapter, formed by graduate and undergraduate students, has been founded with the aim to make Optics and Photonics more visible to the society by means of educational tasks, divulgation lectures, basic experiments and demonstrations. By now, the USC-OSA has carried out several activities for youth education and professional development. In the future, the chapter is planning new activities and recruiting new members in order to guarantee the continuity of the group and the ongoing activities.

\section{ACKNOWLEDGEMENTS}

This work has been sponsored by the Optical Society of America. Authors acknowledge the collaborative efforts of Prof. Salvador Bará Viñas and Faculty of Optics and Optometry of the University of Santiago de Compostela.

\section{REFERENCES}

[1] http://www.osa.org/en-us/foundation/

[2] http://usc.osahost.org/ 